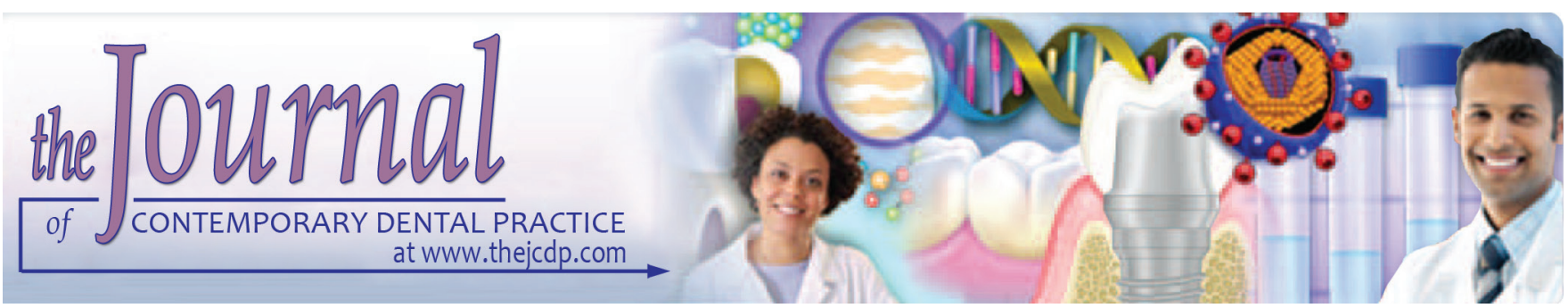

\title{
Effectiveness of the American Board of Orthodontics Discrepancy Index in predicting Treatment Time
}

\author{
1'Dareen Aljehani, ${ }^{2}$ Hosam Ali Baeshen
}

\begin{abstract}
Aim: This study was aimed to explore the effect of pretreatment severity of malocclusion on the duration of the treatment using The American Board of Orthodontics discrepancy index (ABO-DI).

Materials and methods: This clinical retrospective study consisted of orthodontics records of 37 patients who were treated with comprehensive fixed orthodontic appliance from 2011 to 2013. The sample of the study was collected so as to exclude, to the maximum possible, the patient cooperation variability by reviewing all patient chart entries. The DI measurements were used to gather the information of the pretreatment and relate it to the time duration of the treatment. Statistical analyses were performed using the chi-square test and Pearson correlation coefficient.
\end{abstract}

Results: The average treatment time was 24.5 months. The DI scores mean for class I and II was 14.30 and 20.15 respectively. Age and sex did not significantly influence the treatment duration $(p>0.05)$.

Conclusion: The results of this study showed that the ABO-DI could be a useful tool to predict orthodontic treatment time.

Clinical significance: The ABO-DI can significantly aid in orthodontic treatment time planning.

Keywords: American Board of Orthodontics, Discrepancy index, Orthodontic treatment time.

How to cite this article: Aljehani D, Baeshen HA. Effectiveness of the American Board of Orthodontics Discrepancy Index in predicting Treatment Time. J Contemp Dent Pract 2018;19(6):647-650.

${ }^{1}$ Department of Orthodontics, Albatarje College, Jeddah Kingdom of Saudi Arabia

${ }^{2}$ Department of Orthodontics, Faculty of Dentistry, King Abdulaziz University, Jeddah, Kingdom of Saudi Arabia Al-Farabi Private Dental and Nursing College, Jeddah, Kingdom of Saudi Arabia

Corresponding Author: Hosam Ali Baeshen, Department of Orthodontics, Faculty of Dentistry, King Abdulaziz University Jeddah, Kingdom of Saudi Arabia; Al-Farabi Private Dental and Nursing College, Jeddah, Kingdom of Saudi Arabia, Phone: +96626403443, e-mail: habaeshen@kau.edu.sa

\section{Source of support: Nil}

\section{Conflict of interest: None}

\section{INTRODUCTION}

Considerable efforts have been made to develop reliable and standardized measurement tools in orthodontics to assess treatment outcome. Quantitative indices like the peer assessment rating (PAR) and the objective grading system (OGS) have been successfully used so far, but these are limited to occlusal aspects only. ${ }^{1,2}$ The ABO's main goal is clinical excellence, as it aims to deliver high-quality orthodontics. The DI is an objective way of describing the complexity or difficulty of a treatment plan for an orthodontic patient based on clinical findings and measurements recorded from cephalometric and panoramic radiographs and casts. ${ }^{1}$

A common question for patient undergoing orthodontic treatment is "How long will my orthodontic treatment take?" Consequently, it is essential for the orthodontist to understand the factors that influence the treatment time. ${ }^{2}$ The treatment time of comprehensive orthodontic treatment was reported to range between 23.4 and 33.4 months with an average treatment duration of 28.6 months. ${ }^{1-3}$ There are many factors affecting treatment time including sex, degree of crowding, pretreatment ANB angle, Angle's definitions, second molars banding, extraction/ without extraction, oral hygiene, intraoral elastic wear, total number of treatment appointments, failed appointments, number of treatment phases, number of replaced brackets and bands, need of wearing headgear, PAR score, type of appliances, missing teeth, impacted teeth, cephalometric measurements, total number of office visits, number of broken appliances, overjet and overbite before initiating treatment, time between appointments, presence of deciduous dentition, facial height, needing for extractions, or surgical cases, and case difficulty. ${ }^{2-9}$ 
Besides, the orthodontist's skill to correctly predict the duration of treatment time is an essential clinical practicemanagement skill. ${ }^{3}$ Factors affecting the orthodontic treatment duration were assessed with the use of ABO's DI to assess the severity of the pretreatment malocclusion. The treatment complexity index (TCI) was used to assess complexity based on treatment modalities. The Indiana University School of Dentistry comprehensive clinical assessment and the ABO OGS were used to assess the clinical outcomes for the patients undergoing the orthodontic treatment. ${ }^{10}$ Deguchi et al ${ }^{11}$ showed that the PAR and a modified DI are also useful indexes for evaluating the case complexity, but the reliable use of the DI requires the introduction of race-specific cephalometric standards or the development of a weighting system. Campbell et al ${ }^{12}$ found that the DI scores were significantly higher than average for cases of posterior crossbite, anteroposterior discrepancy, and class II, division I malocclusion. Early treatment has longer times and they had the lowest DI average scores. However, Parrish et $\mathrm{al}_{1}^{13}$ when studying the relationship between the $\mathrm{ABO}-\mathrm{DI}$ and treatment duration in a graduate orthodontic clinic, concluded that there was no relationship between DI and treatment time.

The DI, which was developed by the $\mathrm{ABO}$, is an index for assessing case selection to be presented for board certification. The use of this index was to evaluate treatment complexity rather than the treatment need.

Therefore, the objective of this study was to evaluate the effect of pretreatment severity of malocclusion on the duration of the treatment using ABO-DI.

\section{MATERIALS AND METHODS}

In this study, the sample consisted of completed orthodontic patients, selected from the files of Jacksonville University School of Orthodontics from 2011 to 2013. Orthodontic records comprised pretreatment study models, pretreatment cephalometric radiographs, and treatment plans, and treatment daily notes were examined for patients who fulfilled the following inclusion criteria: (1) availability of patients' complete records, (2) patients who completed comprehensive orthodontic treatment with orthodontic multibracket fixed appliance therapy, (3) treatment outcome including class I canine, $2 \mathrm{~mm}$ overbite and $2 \mathrm{~mm}$ overjet, no crowding or spacing, (4) compliant patients with no more than 3 missing appointments, (5) 3 or less visits with broken brackets, and (6) compliance with instructions, such as wearing rubber bands. Exclusion criteria were: (1) phase I treatment (e.g., headgear, functional appliances), (2) limited treatment, (3) craniofacial anomalies, (4) transfers from another orthodontic office, (5) treatment prematurely terminated, and (6) incomplete patient records.
All examination measurements for both lateral cephalometric radiographs and study models were accomplished by one examiner. The study models were analyzed by using the OrthoCAD software (Cadent, Carlstadt, New Jersey, USA). The DI scores were calculated using the formula outlined by Cangiolosi et $\mathrm{al}^{1}$ and established by the ABO guidelines in November 2006.

The OrthoCAD's ABO-DI module was used to locate the points and compute the total scores for the variables of overbite and overjet measurements, occlusal relationships, buccal and lingual crossbites, crowding, anterior openbite, lateral openbite, and other variables. The cephalometric analysis of the radiographs was recorded manually using transparent paper with sharp pencil. The records taken involved ANB, SN-GoGn, and IMP angles.

\section{Statistical Analysis}

The data were analyzed by descriptive statistics using parametric and nonparametric statistics which investigated the correlations between variables. The relationship between categorical and continuous variables was explained using a Pearson correlation coefficient method. The DI score in the predictive model as the independent variables and the different categories of malocclusions used as the dependent variable were analyzed using a one-way analysis of variance (ANOVA).

\section{RESULTS}

A total of 217 records were screened and only 37 patients' records fulfilled the inclusion/exclusion criteria; 24.5 months was the average treatment time for the 37 patients in this study, while 17.7 points were the total average DI score (Table 1); 21.5 months was the average treatment time for class I patients with an average DI score of 14.30 points. On the contrary, in patients with class II, the average treatment time was 29.6 months and the DI score was 20.15 points, which showed a high value (Table 2 ). The average age for patients in the study at the beginning of treatment was 15.7 years. There was no statistically significant difference found between age and gender.

The ANOVA showed that there were differences among molar classifications. There is a statistically significant difference between class I and II patients as shown in Table $3(\mathrm{p}<0.05)$.

Table 1: The average (mean) DI score for males and females in the sample

\begin{tabular}{llll}
\hline Gender & Mean & $n$ & $\begin{array}{l}\text { Standard } \\
\text { deviation }\end{array}$ \\
\hline Male & 17.38 & 13 & 10.532 \\
Female & 17.83 & 24 & 12.193 \\
\hline Total & 17.68 & 37 & 11.489 \\
\hline
\end{tabular}


Effectiveness of the ABO-DI in predicting Treatment Time

Table 2: The average (mean) DI score for different molar classification in the sample

\begin{tabular}{llll}
\hline $\begin{array}{l}\text { Molar } \\
\text { Classification }\end{array}$ & Mean & $n$ & $\begin{array}{l}\text { Standard } \\
\text { deviation }\end{array}$ \\
\hline Class I & 14.30 & 20 & 9.303 \\
Class II & 20.15 & 13 & 13.874 \\
Class III & 26.50 & 4 & 7.724 \\
\hline Total & 17.68 & 37 & 11.489 \\
\hline
\end{tabular}

Table 4: The mean of DI score for those with extraction vs nonextraction

\begin{tabular}{llllll}
\hline & Extraction & $n$ & Mean & $\begin{array}{l}\text { Standard } \\
\text { deviation }\end{array}$ & $\begin{array}{l}\text { Standard } \\
\text { error mean }\end{array}$ \\
\hline Months of & No & 18 & 23.83 & 6.364 & 1.500 \\
treatment & Yes & 19 & 25.16 & 6.466 & 1.483 \\
\hline
\end{tabular}

The correlation coefficient of 0.294 demonstrated a weak correlation, indicating that an increase in DI score corresponds to an increase in the months of treatment. When comparing the mean DI scores for those with extraction (15.39) vs without extraction (19.84), there was no statistically significant difference $(p>0.05)$, even though those with an extraction had higher DI scores. The mean treatment time for class I growing without extraction with DI $\leq 15$ was 21.5 months; however, for class I growing without extraction with DI > 15 was 29 months. For class I growing with extraction, the treatment time was 22 months, while class II growing without extraction with DI $\leq 15$, the treatment time was 21.4 months. For class II growing without extraction with DI $>15$, the treatment time was 32 months. For class II growing with extraction with DI $\leq 15$, the treatment time was 26 months. For class II growing with extraction with DI $>15$, the treatment time was 31.5 months (Table 4).

Table 4 shows only ex $v$ s non-ex for the total sample and it appears that there were no significant differences in treatment time.

\section{DISCUSSION}

The objective of this investigation was to evaluate the effect of pretreatment severity of malocclusion on the duration of the treatment. While several factors attribute to the length of orthodontic treatment, the DI is one procedure that can be used for prediction. ${ }^{13}$ The DI is a dependable index for measuring complexity of malocclusion. ${ }^{14}$ It has been reported that the DI score correlates with increased treatment period. ${ }^{10}$

The design of the present study was to exclude, to the maximum possible, the patient cooperation variability that could influence the duration of the treatment time. It was found that there was a small-to-moderate correlation, indicating that an increase in DI score corresponds to an increase in the months of treatment. The same result is
Table 3: The analysis of variance comparison of DI score by molar classification

\begin{tabular}{llllll}
\hline & $\begin{array}{l}\text { Sum of } \\
\text { squares }\end{array}$ & $\begin{array}{l}\text { Degree of } \\
\text { freedom }\end{array}$ & $\begin{array}{l}\text { Mean } \\
\text { square }\end{array}$ & $f$-value & Significance \\
\hline $\begin{array}{l}\text { Between } \\
\text { groups }\end{array}$ & 619.216 & 2 & 309.608 & 2.547 & 0.093 \\
$\begin{array}{l}\text { Within } \\
\text { groups }\end{array}$ & 4132.892 & 34 & 121.556 & & \\
\hline Total & 4752.108 & 36 & & & \\
\hline
\end{tabular}

found in the study of Vu et al, ${ }^{10}$ when they concluded that the DI and the TCI month sent complexity index (TCIy concluded that the) are sensitive potential indicators of treatment duration. ${ }^{10}$

The average treatment time was 24.5 months in this study. The treatment time averaged for class I patients was 21.5 months and for class II, it was 29.6 months. The patients with mean treatment duration of 30 months and a DI score $>15$ points were significantly longer than those with a DI score $\leq 15$ (22 months). This is almost consistent with the study reported by $\mathrm{Vu}$ et $\mathrm{al}^{10}$ who reported that patients with mean treatment duration of 32.9 months with a DI score $>20$ points being significantly longer than patients with a DI score between 10 and 19 (28.5 months) or less than 10 (26.3 months).

In some studies, for patients with class II that involved a two-phase treatment, the treatment times were $28.61^{3}$ and 31.2 months. ${ }^{15}$ On the contrary, when the two-phase treatment was excepted, the times of treatment were 22.18, 23.12, and 23.53 months. ${ }^{16-18}$

When comparing the demographic data with DI and treatment duration, the result was not statistically significant ( $p>0.05)$. This is consistent with Parrish et al. ${ }^{13}$ Also, it is in agreement with Vu et a ${ }^{10}$ who reported that the treatment time average for females was 1.3 months shorter than for males. However, this difference was not statistically significant $(p=0.22)$. Previous studies have noted that females take shorter time than males. ${ }^{2,18}$ Starnbach and Kaplan ${ }^{19}$ attributed this finding to poor cooperation of males. Our study attempted to exclude the patient compliance variable, and therefore, it could be the reason that no difference in treatment time between gender was observed $(p>0.05)$. Some other studies have stated that the age factor has no influence on treatment time, ${ }^{3,17,20}$ and the present study showed similar findings.

The present study showed that there was a positive weak correlation between DI and treatment time. The Salzmann ${ }^{21}$ Index was used and a correlation was found in the study by Fink and Smith, ${ }^{17}$ while other studies that used the PAR index reported mixed findings. ${ }^{4-6} \mathrm{ADI}$ score of $>15$ points would expect longer treatment time than 22.1 months in almost $85 \%$ of the time as reported by Simister et al..$^{22}$ In comparison of the mean DI scores 
for those with extraction (15.39) vs those without extraction (19.84), no significant difference was observed. This finding is in contrast with a previous study that reported that the treatment time duration for patients with extraction stayed 7.8 months longer than patients who had no extractions. ${ }^{10}$ Based on the number and pattern of extractions, no significant difference was found in treatment duration. ${ }^{10}$

\section{CONCLUSION}

Based on the findings of this study, the following conclusions could be drawn:

- ABO-DI is a useful tool to predict treatment time in addition to other factor, such as appointment timing, type of appliance, compliance, and treatment modality.

- The treatment time averaged in class II patients is 7 months longer than class I.

- There is no influence on the treatment duration by age and gender.

\section{REFERENCES}

1. Cangialosi TJ, Riolo ML, Owens SEJr, Dykhouse VJ, MoffittAH, Grubb JE, Greco PM, English JD, James RD. The ABO discrepancy index: a measure of case complexity. Am J Orthod Dentofacial Orthop 2004 Mar;125(3):270-278.

2. Skidmore KJ, Brook KJ, Thomson WM, Harding WJ. Factors influencing treatment time in orthodontic patients. Am J Orthod Dentofacial Orthop 2006 Feb;129(2):230-238.

3. de Souza RA, de Oliveira AF, Pinheiro SM, Cardoso JP, Magnani MB. Expectations of orthodontic treatment in adults: the conduct in orthodontist/patient relationship. Dent Press J Orthod 2013 Mar-Apr;18(2):88-94.

4. Popowich K, Nebbe B, Heo G, Glover KE, Major PW. Predictors for Class II treatment duration. Am J Orthod Dentofacial Orthop 2005 Mar;127(3):293-300.

5. Stewart JA, Heo G, Glover KE, Williamson PC, Lam EW, Major PW. Factors that relate to treatment duration for patients with palatally impacted maxillary canines. Am J Orthod Dentofacial Orthop 2001 Mar;119(3):216-225.

6. Mascarenhas AK, Vig K. Comparison of orthodontic treatment outcomes in educational and private practice settings. J Dent Educ 2002 Jan;66(1):94-99.

7. Fisher MA, Wenger RM, Hans MG. Pretreatment characteristics associated with orthodontic treatment duration. Am J Orthod Dentofacial Orthop 2010 Feb;137(2):178-186.
8. Mavreas D, Athanasiou AE. Factors affecting the duration of orthodontic treatment: a systematic review. Eur J Orthod 2008 Aug;30(4):386-395.

9. Louwerse TJ, Aartman, IH, Kramer GJ, Prahl-Andersen B. The reliability and validity of the index of complexity, outcome and need for determining treatment need in Dutch orthodontic practice. Eur J Orthod 2006 Feb;28(1):58-64.

10. Vu CQ, Roberts WE, Hartsfield JK Jr, Ofner S. Treatment complexity index for assessing the relationship of treatment duration and outcomes in a graduate orthodontics clinic. Am J Orthod Dentofacial Orthop 2008 Jan;133(1):9.e1-9.e13.

11. Deguchi T, Honjo T, Fukunaga T, Miyawaki S, Roberts WE, Takano-Yamamoto T. Clinical assessment of orthodontic outcomes with the peer assessment rating, discrepancy index, objective grading system, and comprehensive clinical assessment. Am J Orthod Dentofacial Orthop 2005 Apr;127(4):434-443.

12. Campbell CL, Roberts WE, Hartsfield JK Jr, Qi R. Treatment outcomes in a graduate orthodontic clinic for cases defined by the American Board of Orthodontics malocclusion categories. Am J Orthod Dentofacial Orthop 2007 Dec;132(6):822-829.

13. Parrish LD, Roberts WE, Maupome G, Stewart KT, Bandy RW, Kula KS. The relationship between the $\mathrm{ABO}$ discrepancy index and treatment duration in a graduate orthodontic clinic. Angle Orthod 2011 Mar;81(2):192-197.

14. Schafer SM, Maupome G, Eckert GJ, Roberts WE. Discrepancy index relative to age, sex, and the probability of completing treatment by one resident in a 2-year graduate orthodontics program. Am J Orthod Dentofacial Orthop 2011 Jan;139(1):70-73.

15. Vig PS, Orth D, Weintraub JA, Brown C, Kowalski CJ. The duration of orthodontic treatment with and without extractions: a pilot study of five selected practices. Am J Orthod Dentofacial Orthop 1990 Jan;97(1):45-51.

16. Alger DW. Appointment frequency versus treatment time. Am J Orthod Dentofacial Orthop 1988 Nov;94(5):436-439.

17. Fink DF, Smith RJ. The duration of orthodontic treatment. Am J Orthod Dentofacial Orthop 1992 Jul;102(1):45-51.

18. Harrington, CF. Deflection index and duration of treatment. Master Thesis, University of Saint Louis, St. Louis, Missouri. 2004.

19. Starnbach HK, Kaplan A. Profile of an excellent orthodontic patient. Angle Orthod 1975 Apr;45(2):141-145.

20. Robb SI, Sadowsky C, Schneider BJ, BeGole EA. Effectiveness and duration of orthodontic treatment in adults and adolescents. Am J Orthod Dentofacial Orthop 1998 Oct;114(4):383-386.

21. Salzmann JA. Definition and criteria of handicapping malocclusion: a progress report. Am J Orthod Dentofacial Orthop 1966 Mar;52(3):209-212.

22. Simister, BG. A study of treatment duration using the Discrepancy index. Master Thesis, Saint Louis University, St. Louis, Missouri. 2007. 